\title{
Depletion of Macrophages and Dendritic Cells in Ischemic Acute Kidney Injury
}

\author{
${\text { Lawrence } \mathrm{Lu}^{\mathrm{a}} \text { Sarah Faubel }}^{\mathrm{a}}$ Zhibin He$^{\mathrm{a}}$ Ana Andres Hernando ${ }^{\mathrm{a}}$ Alkesh Jani ${ }^{\mathrm{a}}$ \\ Ross Kedl $^{\mathrm{b}}$ Charles L. Edelstein ${ }^{\mathrm{a}}$ \\ ${ }^{a}$ Division of Renal Diseases and Hypertension, University of Colorado at Denver, Aurora, Colo., and ${ }^{\mathrm{b}}$ Department of \\ Immunology, National Jewish Hospital, Denver, Colo., USA
}

\section{Key Words}

Macrophages • Dendritic cells • Ischemia • Acute kidney injury

\begin{abstract}
Background: Inflammation is thought to play a role in ischemic acute kidney injury (AKI). We have demonstrated that macrophage and dendritic cell depletion, using liposomeencapsulated clodronate (LEC), is protective against ischemic AKI. Methods: To determine whether macrophages or dendritic cells or both play a role in ischemic AKI, we performed ischemic AKI in CD11b-DTR mice that have a diphtheria toxin (DT)-induced depletion of CD11b cells (macrophages) and CD11c-DTR mice that have a DT-induced depletion of CD11c cells (dendritic cells). Results: While LEC-treated animals had a significant functional protection from AKI, CD11b-DTR and CD11c-DTR mice were not protected against AKI despite a similar degree of renal macrophage and dendritic cell depletion. Proinflammatory cytokines are known to play a role in ischemic AKI. To determine the possible reasons for the lack of protection in CD11b-DTR and CD11c-DTR mice compared to LEC-treated mice, 32 cytokines/chemokines were measured in these mice. Of the cytokines/chemokines measured, IL-6, MCP-1, GMCSF, IL-1 $\beta$ and CXCL1 (also known as IL-8 in humans or KC in mice) showed significant
\end{abstract}

differences in the LEC-treated, CD11b-DTR and CD11c-DTR mice. MCP-1 and CXCL1 (known mediators of AKI), and also GMCSF and IL-1 $\beta$ were increased in AKI and decreased in LECtreated AKI but not AKI in CD11b-DTR or CD11c-DTR mice. Conclusions: These findings suggest that LEC-mediated protection from AKI is not simply mediated by depletion of renal macrophage or dendritic cell subpopulations. Protection against AKI in LEC-treated compared to CD11b-DTR or CD11c-DTR mice may be partially explained by differences in proinflammatory cytokine profiles.

Copyright $\odot 2012$ S. Karger AG, Basel

\section{Introduction}

Previous studies have demonstrated that ischemic acute kidney injury (AKI) can be ameliorated by administration of liposome-encapsulated clodronate (LEC) prior to initiation of renal ischemia [1-3]. LEC administration to wild-type mice is a well described method to deplete mononuclear phagocytes, known as monocytes in the circulation and macrophages in tissues. Mononuclear phagocytes engulf the clodronate and then die by apoptosis without necrosis or inflammation [4-7]. Although commonly used to study mononuclear phagocytes, administration of LEC also depletes dendritic cells, which

\section{KARGER}

Fax +4161306 1234 E-Mail karger@karger.ch www.karger.com
(ㄷ) 2012 S. Karger AG, Basel

0250-8095/12/0352-0181\$38.00/0

Accessible online at:

www.karger.com/ajn
Charles L. Edelstein

Division of Renal Diseases and Hypertension

University of Colorado at Denver, Box C281

12700 East 19th Ave, Aurora, CO 80262 (USA)

Tel.+1 303724 4810, E-Mail Charles.edelstein@ucdenver.edu 
also engulf clodronate [8-10]. Thus, it is unclear whether the protection against ischemic AKI seen in LEC-administered mice is due to depletion of mononuclear phagocytes, dendritic cells, or both. The individual contribution of macrophages or dendritic cells in the kidney to the pathophysiology of ischemic AKI is unknown and is the focus of the present study.

Macrophages and dendritic cells originate from a common progenitor mononuclear phagocyte system in bone marrow. Both macrophages and dendritic cells are antigen-presenting cells and play an important role in initiating innate immune responses and generating adaptive immunity. Macrophages and dendritic cells share many surface markers and properties essential to defense and tissue remodeling and repair. Both macrophages and dendritic cells are found in normal renal tissue and their populations increase in various renal diseases where they are involved in initiation and progression of renal diseases.

In the present study, we examined different strategies aimed at depleting renal macrophages and dendritic cells, utilizing LEC administration versus transgenic mice expressing diphtheria toxin (DT) receptors (DTR) under the promoters for either $\mathrm{CD} 11 \mathrm{~b}$ or $\mathrm{CD} 11 \mathrm{c}$, with the presumption that DT injection to CD11b-DTR transgenic mice would more selectively deplete mononuclear phagocytes, while DT injection to CD11c-DTR transgenic mice would more selectively deplete dendritic cells. Due to the well described proinflammatory effects of mononuclear phagocytes, we hypothesized that mononuclear phagocyte depletion using LEC or CD11b-DTR mice would protect against AKI whereas dendritic cell depletion in CD11c-DTR mice would not. We utilized flow cytometry to confirm renal cell depletion and to better characterize the resident leukocytes in the setting of AKI. To our knowledge, this is the first study to examine ischemic AKI in CD11b-DTR and CD11c-DTR mice.

\section{Methods}

Mice and Injections

Adult male mice 8-10 weeks of age weighing 20-25 g were used for all experiments. Wild-type C57/B6, wild-type Balb/c, and CD11b-DTR transgenic mice on the Balb/c background were purchased from The Jackson Laboratory. CD11c-DTR transgenic mice on the C57/B6 background were provided by Dr. Ross Kedl.

\section{Cell Depletion}

To deplete DTR-expressing cells, the DTR transgenic mice were injected IV via the tail vein with DT $(25 \mathrm{ng} / \mathrm{kg}$ body weight for CD11b-DTR and $4 \mathrm{ng} / \mathrm{kg}$ body weight for CD11c-DTR) $18 \mathrm{~h}$ prior to surgery. Controls included wild-type mice injected with
DT and transgenic mice injected with equivalent volume of PBS. To deplete phagocytic cells, mice were injected via their tail veins with $200 \mu \mathrm{l}$ of LEC 5 and 2 days prior to surgery. Control animals were injected with the same volume of empty liposome on the same days. Empty liposomes (vehicle) and LEC were prepared as previously described in detail [4-7]. Clodronate (clodronic acid) [(dichloromethylene) bisphosphonic acid] $(\mathrm{CH} 4 \mathrm{Cl} 2 \mathrm{O} 6 \mathrm{P} 2)$ was obtained from Roche Diagnostics GmbH (Mannheim, Germany).

\section{Ischemia Protocol}

The operator was blinded to treatment groups. Mice were anesthetized with IP Avertin (2,2,2-tribromoethanol; Aldrich, Milwaukee, Wisc., USA). A midline incision was made and the renal pedicles were bilaterally clamped for 24 min with microaneurysm clamps. The time of ischemia was chosen to obtain a reversible model of ischemic acute renal failure and avoid animal mortality. Serum creatinine reaches a peak at $24-48 \mathrm{~h}$ of reperfusion and then gradually returns to normal within 3-7 days. This model is well established in our laboratory $[3,26]$. After clamp removal, kidneys were observed for restoration of blood flow by the return to their original color. The abdomen was closed in two layers. Sham surgery consisted of the same surgical procedure except that clamps were not applied. During the first $24 \mathrm{~h}$ of the reperfusion period, the animals were kept in an incubator at $29^{\circ} \mathrm{C}$. Animals were sacrificed at $24 \mathrm{~h}$ after ischemia for all the measurements performed in the study. Blood samples were obtained at sacrifice via cardiac puncture.

\section{Cell Preparation, Staining, and FACS Analysis}

Kidneys were removed and placed into wells of a 6 -well plate containing $2 \mathrm{ml}$ of click's (EHAA) medium containing collagenase $\mathrm{D}(0.5 \mathrm{mg} / \mathrm{ml})$ and DNase $(50 \mu \mathrm{g} / \mathrm{ml})$, and teased apart with forceps. Plates were incubated at $37^{\circ} \mathrm{C}$ for $40 \mathrm{~min}$, after which $2 \mathrm{ml}$ of $0.1 \mathrm{M}$ EDTA (in HBSS) was added to each well and incubated an additional $5 \mathrm{~min}$ at $37^{\circ} \mathrm{C}$. The cell suspension was passed through a strainer into a $50-\mathrm{ml}$ tube and washed with $5 \mathrm{mM}$ EDTA (in HBSS). Cells were pelleted by centrifugation and subsequently resuspended briefly in ammonium chloride buffer to lyse RBC. Cells were then washed and resuspended in HBSS containing $5 \mathrm{mM}$ EDTA and $0.1 \%$ FBS. Fc receptors were first blocked by incubating cells with anti-CD16/32. Cells were then stained with conjugated antibodies of interest for at least $30 \mathrm{~min}$ at $4^{\circ} \mathrm{C}$ and then washed twice in FACS buffer (PBS containing $0.1 \%$ FBS and $0.1 \%$ sodium azide). Live cell counts were obtained on sample aliquots using a hemocytometer. Six-color flow cytometry was performed on a CyAn LX flow cytometer (DakoCytomation) and analyzed with Weasel version 2.2 software (The Walter and Eliza Hall Institute of Medical Research, Melbourne, Australia).

\section{Antibodies}

For flow cytometry studies the following antibodies were used: CD11b PerCP-Cy5.5 (clone M1/70) was purchased from BD Pharmingen. I-A/I-E allophycocyanin (clone M5/114.15.2), and CD11c allophycocyanin-Alexa Fluor 750 (clone HL3) were purchased from eBioscience. F4/80 PE (clone BM8) and CD45 Pacific Blue (clone 30-F11) were purchased from Biolegend.

\section{Serum Creatinine and BUN Measurement}

Serum creatinine and BUN were measured using an Astra autoanalyzer (Beckman Instruments, Fullerton, Calif., USA). Urea 
is detected with a kinetic urease method. A conductivity electrode measures the rate of urea formation. Creatinine is determined with a kinetic Jaffe method. A photometer measures the color formed.

\section{Renal Cytokines}

Frozen tissue samples (1/2 kidney) were homogenized in 500 $\mu l$ of cell lysis buffer (Bio-Rad, Hercules, Calif., USA) containing $0.4 \% 500 \mathrm{~mm}$ phenylmethylsulfonyl fluoride (PMSF) and $1 \%$ protease inhibitor cocktail (Sigma, St. Louis, Mo., USA). Samples were sonicated (model VC500; Sonics \& Materials, Danbury, Conn., USA) on ice using 5 five-second pulses with time allowed for samples to cool between pulses. Samples were then centrifuged at 4,500 $\mathrm{g}$ for $15 \mathrm{~min}$ at $4^{\circ} \mathrm{C}$. Supernatants were collected, analyzed for protein content using a Bio-Rad DC protein assay kit (Hercules, Calif., USA) with bovine serum albumin as standards, and stored at $-20^{\circ} \mathrm{C}$ until use.

Renal cytokines were determined using two bead-based multiplex cytokine kits (Bio-Rad, Hercules, Calif., USA) in conjunction with flow-based protein detection and the Luminex LabMAP multiplex system (Luminex, Austin, Tex., USA) according to manufacturer's directions. This technique allows the detection of these cytokines with $20 \mu \mathrm{l}$ of a single sample. The detection limit for each cytokine was $1.95 \mathrm{pg} / \mathrm{ml}$. Values are reported as $\mathrm{pg} / \mathrm{mg}$ tissue protein. Two separate multiplex kits were utilized, a 23-plex kit and a 9-plex kit. The 23-plex kit measured IL-1 $\alpha$, IL-1 $\beta$, IL-2, IL-3, IL-4, IL-5, IL-6, IL-9, IL-10, IL-12 (p40), IL-12 (p70), IL-13, IL-17, eotaxin, GCSF, GMCSF, IFN- $\gamma$, CXCL1, MCP-1, MIP-1 $\alpha$, MIP-1 $\beta$, RANTES, and TNF- $\alpha$. The 9-plex kit measured IL-15, IL-18, GFG-basic, LIF, MCSF, MIG, MIP-2, PDGF-bb, and VEGF.

\section{Statistical Analysis}

Non-normally distributed data were analyzed by the nonparametric unpaired Mann-Whitney test. Multiple group comparisons were performed using analysis of variance with post-test according to Newman-Keuls. A p value $\leq 0.05$ was considered statistically significant. Values are expressed as means \pm SE.

\section{Results}

\section{Flow Cytometry Analysis of Renal Leukocytes}

Due to the high levels of autofluorescence from digested renal tissue and our interest in renal leukocytes, events were first selected for CD45 (common leukocyte antigen) and then further gated on forward and side scatter patterns to eliminate dead cells or debris. CD45+ gated events were further analyzed for expressions of CD11b (myeloid lineage marker) and I-A/I-E (murine major histocompatibility complex [MHC] II) suggesting antigenpresenting cell (APC) function. APCs (CD11b+ I-A/I-E+ cells) were further analyzed for F4/80 (macrophage marker) expression and CD11c (dendritic cell marker). These resident cells demonstrated uniform and moderate levels of CD11c but had varying levels of F4/80 expression. For characterization purposes we defined renal macrophages as F4/80-high and renal dendritic cells as CD11c positive and F4/80-low (fig. 1A, B).

CD11b+, I-A/I-E+, F4/80+ cells (now referred to as renal macrophages) remained largely unchanged with AKI (fig. 2A-C). These renal macrophages were significantly depleted with LEC treatment and with DT treatment in CD11b-DTR and CD11c-DTR mice (fig. 2A-C). CD11b+, I-A/I-E+, CD11c+ and F4/80-low cells were referred to as renal dendritic cells. These renal dendritic cells were significantly depleted with LEC treatment and with DT treatment in CD11b-DTR and CD11c-DTR mice (fig. 3A-C).

\section{Renal Dysfunction Reflected by Serum Creatinine and} $B U N$ Elevation after AKI

While LEC pretreatment leads to significant functional protection from AKI, neither DT-injected CD11b-DTR nor CD11c-DTR mice were protected against AKI as measured by serum creatinine and BUN (fig. 4).

\section{Diphtheria Toxin Injection to Wild-Type Mice with AKI}

To determine if DT injection itself were injurious in the setting of AKI, thus explaining the lack of renal protection in the DT-injected models, vehicle versus DT was injected intravenously to wild-type mice with AKI and serum creatinine, and renal expression of the proinflammatory cytokines CXCL1 and IL- 6 were determined. Serum creatinine, renal CXCL1, and renal IL- 6 were statistically similar in vehicle versus DT-injected mice with AKI at both 4 and $24 \mathrm{~h}$ post-procedure. Thus, DT injection itself does not appear to be nephrotoxic.

Specifically, serum creatinine was $0.4 \pm 0.0$ after vehicle injection and was $0.4 \pm 0.0$ after DT injection in wild-type mice with AKI $4 \mathrm{~h}$ post-procedure ( $\mathrm{p}=0.99$, $\mathrm{n}=5$ ). Renal CXCL1 (pg/mg) was $194 \pm 41$ in vehicleinjected and $193 \pm 44$ in DT-injected mice with AKI $4 \mathrm{~h}$ post-procedure ( $\mathrm{p}=0.99, \mathrm{n}=9-10)$; and was $115 \pm 45$ in vehicle-injected and $234 \pm 23$ in DT-injected mice with AKI $24 \mathrm{~h}$ post-procedure $(\mathrm{p}=0.17, \mathrm{n}=4)$. Renal IL-6 (pg/ $\mathrm{mg}$ ) was $14 \pm 3$ in vehicle-injected and $17 \pm 2$ in DT injected mice with AKI $4 \mathrm{~h}$ post-procedure $(\mathrm{p}=0.47, \mathrm{n}=$ 9-10) and was $3 \pm 1$ in vehicle-injected mice with AKI and $11 \pm 5$ in DT-injected mice $24 \mathrm{~h}$ post-procedure $(\mathrm{p}=$ $0.2, n=4)$.

\section{Cytokine Profiles}

Of the 32 cytokines measured (see Methods section), only those cytokines/chemokines that demonstrated changes with AKI are shown in the figures. The effect of ischemic AKI on cytokines/chemokines in LEC-treated 


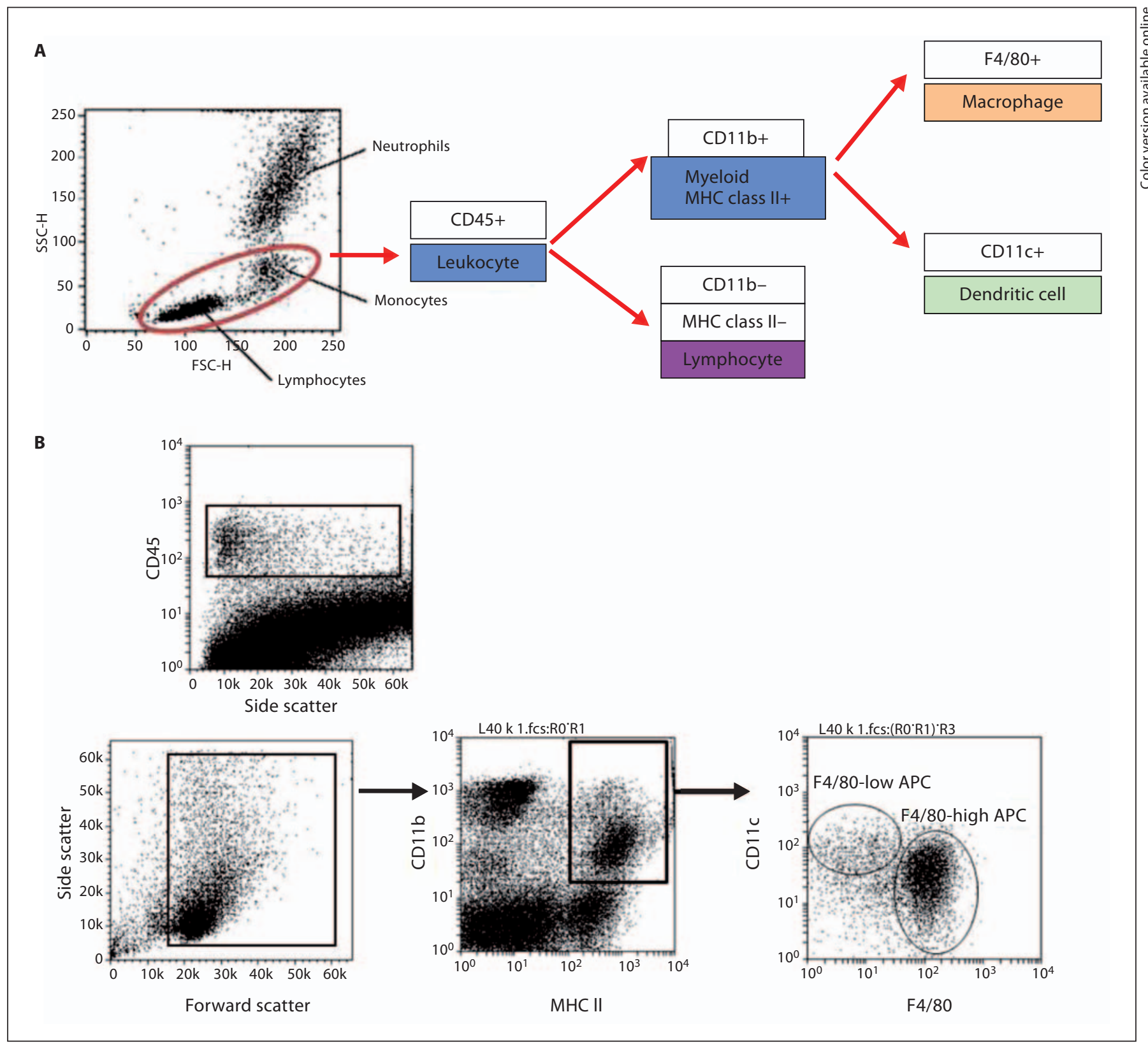

Fig. 1. Gating strategy. Overall gating strategy is shown in A. Flow plots are shown in B. Events were first selected for CD45 (common leukocyte antigen) and then further gated on forward and side scatter patterns to eliminate dead cells or debris. CD45 \pm gated events were further analyzed for expressions of CD11b (myeloid lineage marker) and I-A/I-E (murine major histocompatibility complex [MHC] II) suggesting antigen-presenting cell (APC) function. APCs (CD11b+ I-A/I-E+ cells) were further analyzed for F4/80 (macrophage marker) expression and CD11c (dendritic cell marker) expression. Renal macrophages are defined as F4/80-high APC and renal dendritic cells as F4/80-low APC. CD11b low, I-A/IE-low cells that include lymphocytes were excluded from analysis. mice is demonstrated in figure 5. There were increases in IL-1 $\beta$, IL-6, CXCL1, GMCSF and MCP-1 in vehicle-treated mice with AKI compared to sham. In contrast to $\mathrm{CD} 11 \mathrm{~b}$ or CD11c depletion that did not result in a decrease in multiple cytokines, LEC treatment with AKI resulted in a significant decrease in IL-1 $\beta$, CXCL1, GMCSF and MCP-1 compared to AKI plus vehicle (fig. 5). The effect of ischemic AKI on cytokines/chemokines in CD11b-DTR mice is demonstrated in figure 6 . There were increases in IL-1 $\beta$, IL-6, GMCSF and MCP-1 in CD11b- 


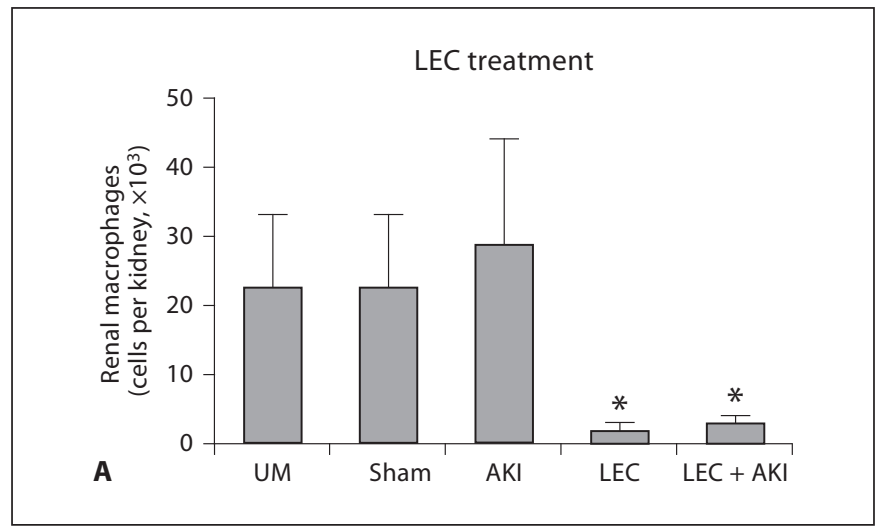

Fig. 2. Quantitative analysis of renal macrophages. There was no significant change in the resident CD11b+, I-A/I-E+, F4/80+ cells in AKI vs. sham or unmanipulated kidneys. With LEC treatment (A) or DT treatment in CD11b-DTR (B) or CD11c-DTR mice (C), there was a significant decrease in renal CD11b+, I-A/I-E+, F4/80+ cells. This depletion was persistent at $24 \mathrm{~h}$ after AKI. ${ }^{*} \mathrm{p}<0.05$ vs. unmanipulated, sham, AKI.

DTR mice with AKI. Depletion of CD11b+ cells with DT resulted in a decrease in IL-6, an increase in MCP-1 and no change in IL-1 $\beta$ and GMCSF (fig. 6). The effect of ischemic AKI on cytokines/chemokines in CD11c-DTR mice is demonstrated in figure 7. There were increases in IL$1 \beta$, IL-6, CXCL1 and MCP-1 in CD11c-DTR mice with AKI. Depletion of CD11c cells had no effect on the increase of IL-1 $\beta$, IL-6, CXCL1 and MCP-1 (fig. 7).

IL-1 $\beta$ in sham mice was lower in CD11b mice compared to wild-type and CD11c mice. The decrease did not reach statistical significance. The decrease in IL-1 $\beta$ in CD11b mice may be related to the fact that the CD11b mice were in the Balb/c background while the wild-type and CD11c mice were in the C57/B6 background.

\section{Discussion}

Utilizing flow cytometry, we were able to identify resident renal leukocytes, characterized by constitutive high expressions of CD11b and I-A/I-E, similar to APCs in other peripheral nonlymphoid organs. These resident re-
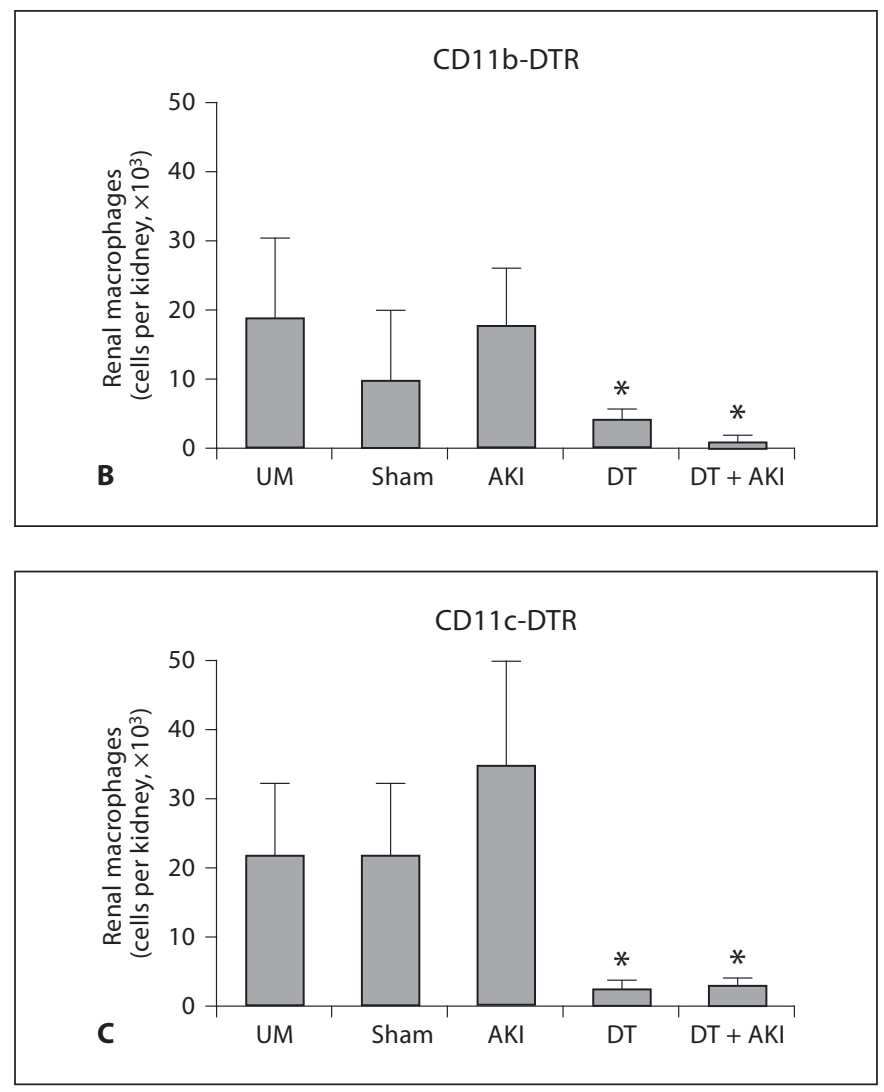

nal leukocytes expressed F4/80 (macrophage marker) and CD11c (dendritic cell marker) in an overlapping pattern. To our surprise, renal macrophages (F4/80-high) and renal dendritic cells (F4/80-low) were both depleted by a similar degree in CD11c-DTR as well as LEC-treated and CD11b-DTR mice. However, protection from renal dysfunction measured by serum creatinine and BUN levels was not similar. While LEC-treated animals had a significant functional protection from AKI, DT-injected CD11b-DTR and CD11c-DTR mice suffered similar degrees of renal dysfunction following AKI. Thus, these data suggest that LEC-mediated protection from AKI is not simply mediated by depletion of renal macrophages and dendritic cells which are capable of producing proinflammatory mediators after AKI.

One potential explanation for renal protection observed in LEC treatment but not in DT transgenic models is that DT injection itself may be nephrotoxic. We investigated this possibility and found that serum creatinine and renal cytokines (IL- 6 and CXCL1) were similar in vehicle-injected mice with AKI versus DT-injected mice with AKI; thus DT itself is not nephrotoxic as judged by 

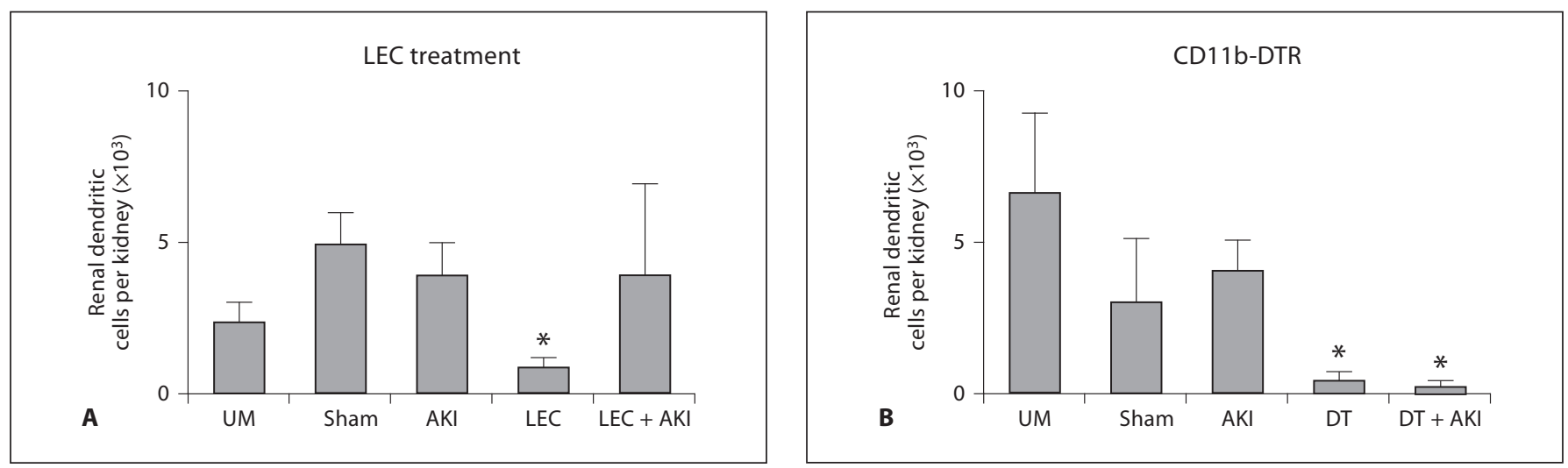

Fig. 3. Quantitative analysis of renal dendritic cells. There was no significant change in the resident $\mathrm{CD} 11 \mathrm{~b}+, \mathrm{I}-\mathrm{A} / \mathrm{I}-\mathrm{E}+, \mathrm{F} 4 / 80_{-}$, CD11c+ cells in AKI vs. sham or unmanipulated kidneys. With LEC treatment there was depletion in non-AKI, but no depletion in AKI (A). With DT treatment in CD11b-DTR (B) or CD11c-DTR mice $(\mathbf{C})$, there was a significant decrease in renal CD11b+, I-A/ $\mathrm{I}-\mathrm{E}+, \mathrm{F} 4 / 80+$ cells. This depletion was persistent at $24 \mathrm{~h}$ after AKI. ${ }^{*} \mathrm{p}<0.05$ vs. unmanipulated, sham, AKI.
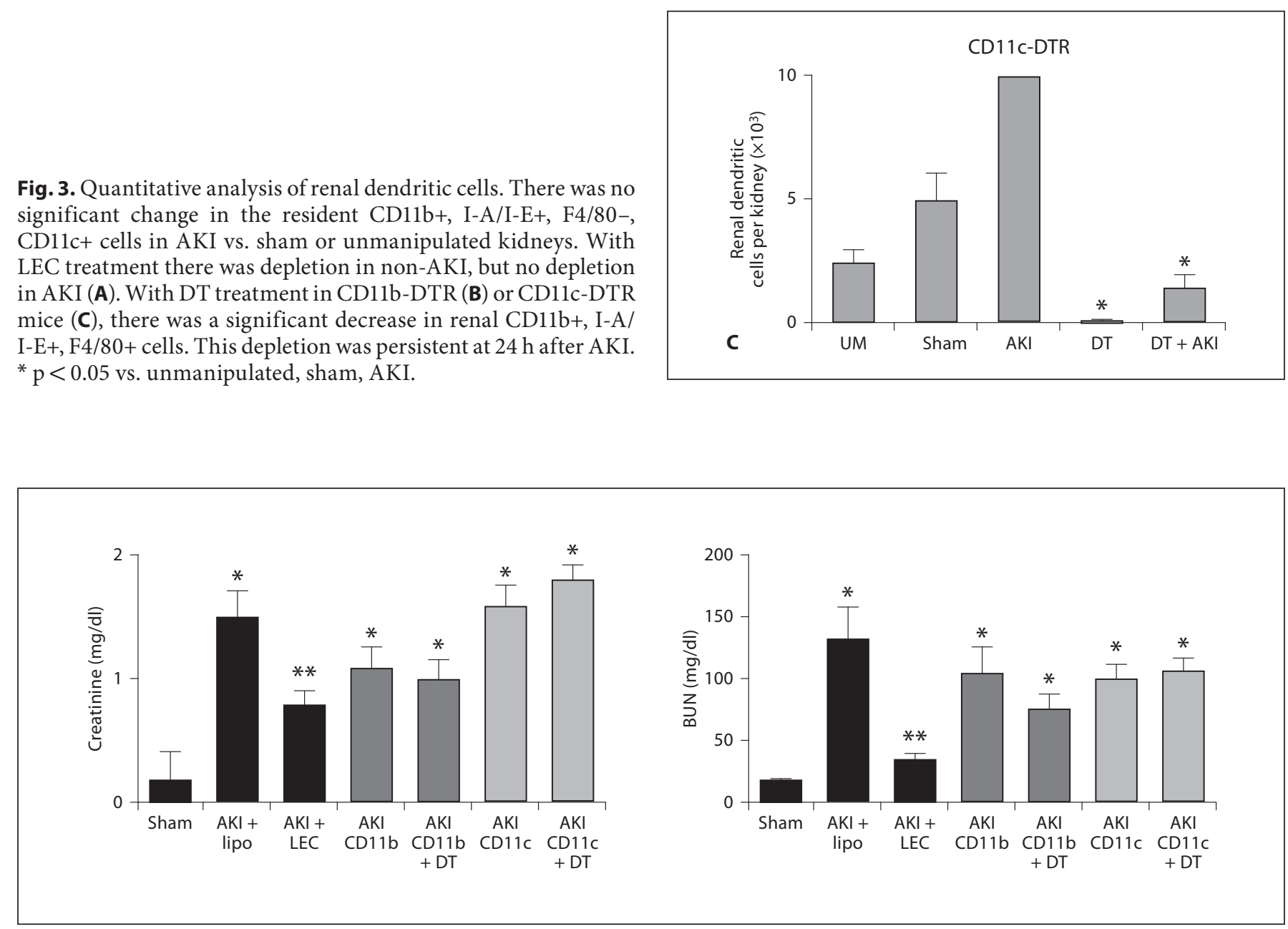

Fig. 4. Serum creatinine and BUN. LEC pretreatment leads to significant functional protection from AKI as measured by serum creatinine and BUN. APC depletion via CD11c-DTR or CD11b-DTR strategies did not result in significant protection. ${ }^{*} \mathrm{p}<0.01$ vs. sham, ${ }^{* *} \mathrm{p}<0.01 \mathrm{vs.}$ AKI + empty liposome (lipo). 


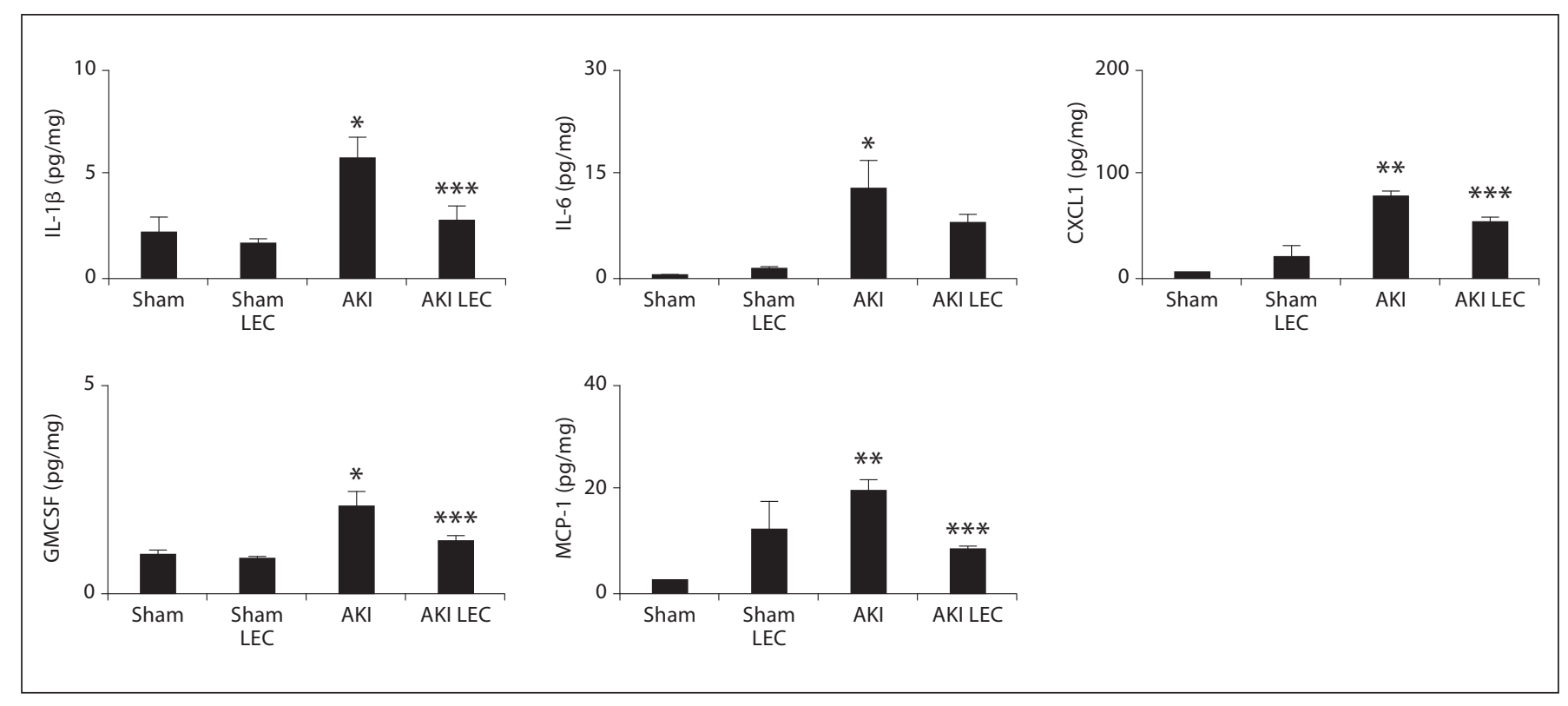

Fig. 5. Cytokine levels in kidney in LEC-treated wild-type mice. There were increases in IL-1 $\beta$, IL-6, CXCL1, GMCSF and MCP-1 in vehicle-treated mice with AKI compared to sham. LEC treatment with AKI resulted in a significant decrease in IL-1 $\beta$, CXCL1, GMCSF and MCP-1 compared to AKI plus vehicle. ${ }^{*} \mathrm{p}<0.05$ vs. sham, ${ }^{* *} \mathrm{p}<0.01$ vs. sham, ${ }^{* * *} \mathrm{p}<0.05$ vs. AKI.

these parameters. Another explanation is that further differentiations amongst these renal macrophages exist beyond their F4/80 or CD11c expression. Thirdly, these different depletion strategies, while leading to similar patterns of depletion in renal macrophages and dendritic cells, may have different depletion patterns of nonrenal leukocytes thus implicating the potential role in AKI of macrophages and dendritic cells in nonrenal organs Lastly, dendritic cells may not be injurious as previously thought $[11,12]$ but may be protective in AKI. As evidence of the protective role of dendritic cells in AKI, CD11c-DTR mice depleted of dendritic cells before cisplatin treatment had worse AKI, tubular injury, neutrophil infiltration and higher mortality than nondepleted mice [13]. In a follow-up study, chimeric mice lacking IL10 in dendritic cells had worse renal dysfunction than chimeric mice positive for IL-10 in dendritic cells suggesting that IL-10 produced by dendritic cells accounts for a portion of the protective effect of dendritic cells in cisplatin-induced AKI [14]. In the same study, Reeves et al. did not see an increase in IL-10 mRNA in the kidney at $24 \mathrm{~h}$ after cisplatin administration [14]. In the present study, there was no significant change in IL-10 in the kidney at $24 \mathrm{~h}$ after ischemia in any of our models. It is possible that changes in IL-10 occur at earlier or later time points. However, in a recent study, we did not see increases in IL-10 mRNA in the kidney in the first $6 \mathrm{~h}$ after ischemia [15].

Our data suggest that labeling of resident renal antigen-presenting cells as either macrophages or dendritic cells should still be open to debate, as strategies aimed at differential depletion of one or the other cell type led to similar patterns of depletion. Previous studies have shown that magnetic bead-enriched renal leukocytes for CD11c also express F4/80 and have other phenotypic and functional characteristics of immature dendritic cells rather than macrophages [16]. Depletion of renal macrophages in CD11c-DTR mice after DT treatment also suggests they may be more dendritic cell-like. However, their similar depletion within CD11b-DTR mice after DT treatment may also suggest macrophage-like lineage. Our findings underscore the limitations of associating cell types and functional behaviors with a few selected surface markers, as our data demonstrate the unexpected changes after LEC- and DT-mediated depletions. Thus, caution must be used to interpret findings using only few broadly expressed surface markers such as CD11b, CD11c or I-A/I-E.

Inflammatory mediators and proinflammatory cytokines play an injurious role in the pathophysiology of 


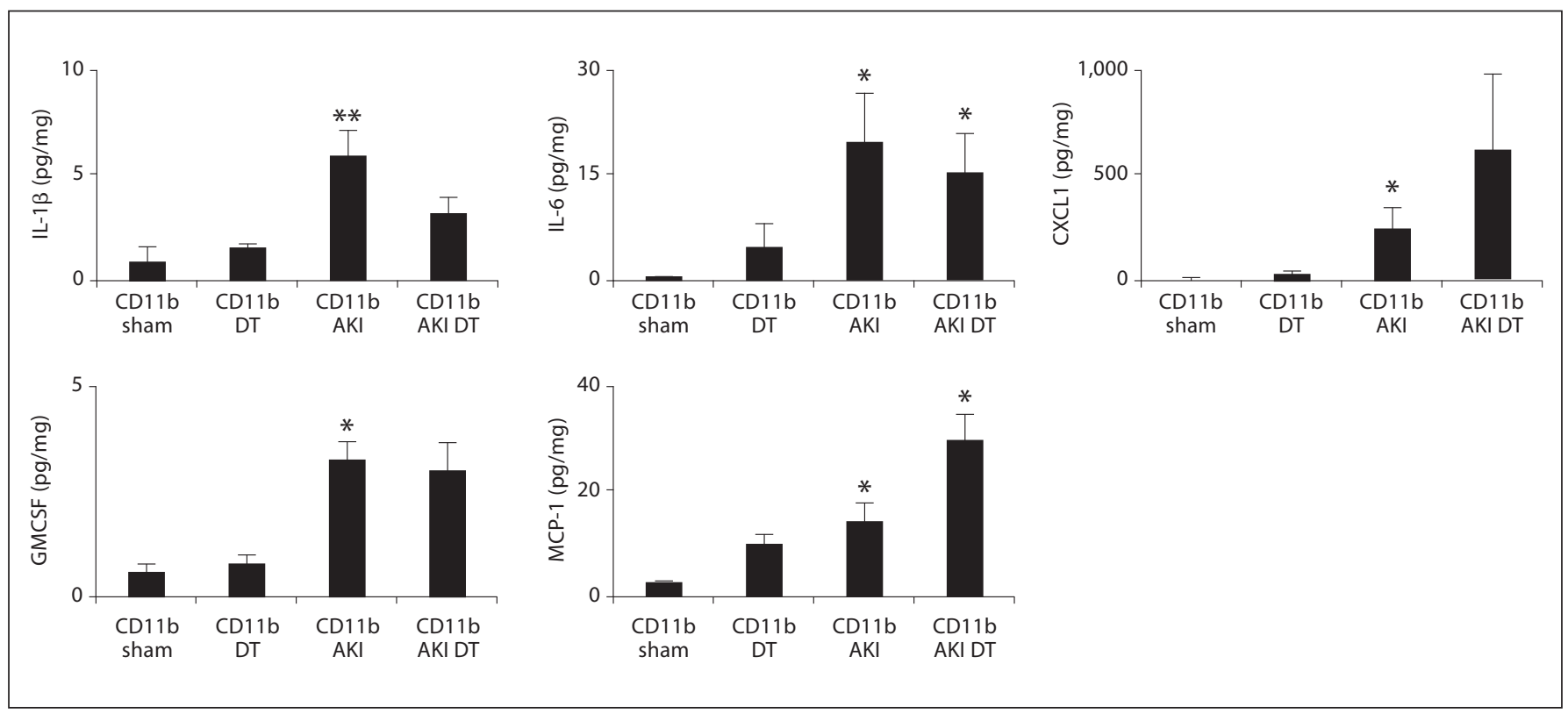

Fig. 6. Cytokine levels in kidney in CD11b mice. There were increases in IL-1 $\beta$, IL-6, GMCSF and MCP-1 in CD11b-DTR mice with AKI. Depletion of CD11b+ cells with DT resulted in a decrease in IL-6, an increase in MCP-1 and no change in IL-1 $\beta$ and GMCSF. ${ }^{*} \mathrm{p}<0.05$ vs. sham, ${ }^{* *} \mathrm{p}<0.01$ vs. sham.

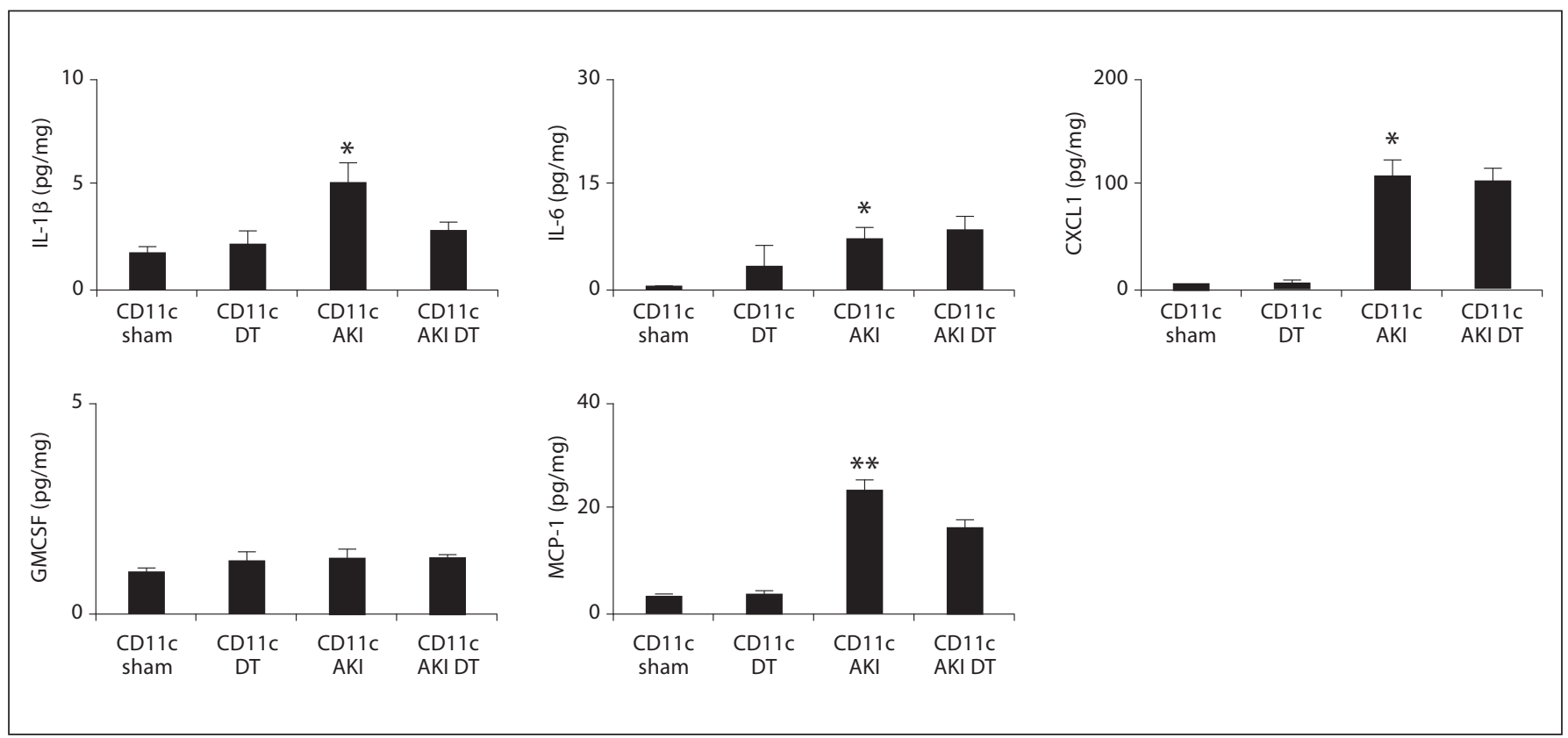

Fig. 7. Cytokine levels in kidney in CD11c mice. There were increases in IL-1 $\beta$, IL-6, CXCL1 and MCP-1 in CD11c-DTR mice with AKI. Depletion of CD11c cells had no effect on the increase of IL-1 $\beta$, IL-6, CXCL1 and MCP-1. ${ }^{*} \mathrm{p}<0.05$ vs. sham, ${ }^{* *} \mathrm{p}<0.001$ vs. sham. 
AKI $[17,18]$. As renal leukocyte depletion patterns did not explain the protection against renal dysfunction, we measured renal cytokine profiles in the LEC-treated, CD11bDTR and CD11c-DTR mice in order to uncover potential mechanisms of protection. Notably, LEC treatment resulted in a decrease in the cytokines IL-1 $\beta$, CXCL1, GMCSF and MCP-1 in AKI that was not seen in the CD11b-DTR and CD11c-DTR mice. The neutrophil chemokine CXCL1 is a well-known mediator of ischemic AKI as inhibition with repertaxin [19] or antibodies to CXCL1 [20] is protective. Also, inhibition of MCP-1/ CCR2 signaling results in protection against ischemic $\mathrm{AKI}$ demonstrating the injurious role of MCP-1 in AKI [21]. Ischemia induces an increase in GMCSF in the kidney [22]. However, IL-1 $\beta$ inhibition is not protective in ischemic [23], endotoxemia-induced [24] or cisplatin-induced AKI [25]. Thus it is possible that the protection against ischemic AKI with LEC is due to a decrease in CXCL1, GMCSF and/or MCP-1.

In summary, LEC treatment, DT treatment of CD11bDTR and CD11c-DTR transgenic mice led to similar depletions of renal APCs (CD11b+, I-A/I-E+, CD11c+, F4/80+/-) in ischemic AKI. Surprisingly, however, only the LEC-treated animals had a significant functional protection from AKI. To investigate the reason for the lack of protection in CD11b and CD11c-DTR mice, pro- inflammatory cytokines/chemokines were measured. Cytokines/chemokines that are thought to be injurious in AKI like MCP-1, GMCSF and CXCL1, were increased in AKI and decreased in LEC-treated AKI but not AKI in DT injected CD11b-DTR or CD11c-DTR mice. In conclusion, protection against AKI in LEC-treated versus CD11b-DTR or CD11c-DTR mice is not purely explained by differences in renal APCs but may be partially explained by differences in proinflammatory cytokines.

\section{Acknowledgements}

This work was supported by RO1DK056851 and RO1DK056851S1 to C.L.E., KO8DK069512 to A.J., R01HL095363 to S.F., AI06877 and AI066121 to R.K. and F32DK079547-01 to L.L. A.A.H. was supported by a post-doctoral grant from the American Heart Association (AHA).

\section{Disclosure Statement} close.

\section{References}

1 Day YJ, Huang L, Ye H, Linden J, Okusa MD: Renal ischemia-reperfusion injury and adenosine $2 \mathrm{~A}$ receptor-mediated tissue protection: role of macrophages. Am J Physiol Renal Physiol 2004;288:F722-F731.

2 Jo SK, Sung SA, Cho WY, Go KJ, Kim HK: Macrophages contribute to the initiation of ischemic acute renal failure in rats. Nephrol Dial Transplant 2006;21:1231-1239.

- 3 He Z, Altmann C, Hoke TS, Ljubanovic D, Jani A, Dinarello CA, Faubel S, Edelstein CL: Interleukin-18 (IL-18) binding protein transgenic mice are protected against ischemic AKI. Am J Physiol Renal Physiol 2008; 295:F1414-F1421.

-4 Van Rooijen N, Kors N, vd EM, Dijkstra CD: Depletion and repopulation of macrophages in spleen and liver of rat after intravenous treatment with liposome-encapsulated dichloromethylene diphosphonate. Cell Tissue Res 1990;260:215-222.

-5 Van Rooijen N, Sanders A: Liposome mediated depletion of macrophages: mechanism of action, preparation of liposomes and applications. J Immunol Methods 1994;174:83-93.
6 Van Rooijen N, Sanders A: Kupffer cell depletion by liposome-delivered drugs: comparative activity of intracellular clodronate, propamidine, and ethylenediaminetetraacetic acid. Hepatology 1996;23:1239-1243.

7 Van Rooijen N, Sanders A: Elimination, blocking, and activation of macrophages: three of a kind? J Leukoc Biol 1997;62:702709.

8 Cho WY, Choi HM, Lee SY, Kim MG, Kim HK, Jo SK: The role of Tregs and CD11c(+) macrophages/dendritic cells in ischemic preconditioning of the kidney. Kidney Int 2010; 78:981-992.

-9 Kitamoto K, Machida Y, Uchida J, Izumi Y, Shiota M, Nakao T, Iwao $\mathrm{H}$, Yukimura T, Nakatani T, Miura K: Effects of liposome clodronate on renal leukocyte populations and renal fibrosis in murine obstructive nephropathy. J Pharmacol Sci 2009;111:285292.

10 Rabinovich GA, Riera CM, Iribarren P: Granulocyte-macrophage colony-stimulating factor protects dendritic cells from liposome-encapsulated dichloromethylene di- phosphonate-induced apoptosis through a Bcl-2-mediated pathway. Eur J Immunol 1999;29:563-570.

11 Nelson PJ: Renal ischemia-reperfusion injury: renal dendritic cells loudly sound the alarm. Kidney Int 2007;71:604-605.

12 Dong X, Swaminathan S, Bachman LA, Croatt AJ, Nath KA, Griffin MD: Resident dendritic cells are the predominant TNF-secreting cell in early renal ischemia-reperfusion injury. Kidney Int 2007;71:619-628.

13 Tadagavadi RK, Reeves WB: Renal dendritic cells ameliorate nephrotoxic acute kidney injury. J Am Soc Nephrol 2010;21:53-63.

14 Tadagavadi RK, Reeves WB: Endogenous IL10 attenuates cisplatin nephrotoxicity: role of dendritic cells. J Immunol 2010;185:49044911.

- 15 Andres-Hernando A, Altmann C, Ahuja N, Lanaspa MA, Nemenoff R, He Z, Ishimoto T, Simpson PA, Weiser-Evans MC, Bacalja J, Faubel S: Splenectomy exacerbates lung injury after ischemic acute kidney injury in mice. Am J Physiol Renal Physiol 2011; 301:F907-F916. 
16 Dong X, Swaminathan S, Bachman LA, Croatt AJ, Nath KA, Griffin MD: Resident dendritic cells are the predominant TNF-secreting cell in early renal ischemia-reperfusion injury. Kidney Int 2007;71:619-628.

17 Sharfuddin AA, Molitoris BA: Pathophysiology of ischemic acute kidney injury. Nat Rev Nephrol 2011;7:189-200.

-18 Lee DW, Faubel S, Edelstein CL: Cytokines in acute kidney injury (AKI). Clin Nephrol 2011;76:165-173.

-19 Cugini D, Azzollini N, Gagliardini E, Cassis P, Bertini R, Colotta F, Noris M, Remuzzi G, Benigni A: Inhibition of the chemokine receptor CXCR2 prevents kidney graft function deterioration due to ischemia/reperfusion. Kidney Int 2005;67:1753-1761.
20 Miura M, Fu X, Zhang QW, Remick DG, Fairchild RL: Neutralization of Gro alpha and macrophage inflammatory protein-2 attenuates renal ischemia/reperfusion injury. Am J Pathol 2001;159:2137-2145.

-21 Furuichi K, Gao JL, Horuk R, Wada T, Kaneko S, Murphy PM: Chemokine receptor CCR1 regulates inflammatory cell infiltration after renal ischemia-reperfusion injury. J Immunol 2008;181:8670-8676.

-22 Zhang Y, Woodward VK, Shelton JM, Richardson JA, Zhou XJ, Link D, Kielar ML, Jeyarajah DR, Lu CY: Ischemia-reperfusion induces G-CSF gene expression by renal medullary thick ascending limb cells in vivo and in vitro. Am J Physiol Renal Physiol 2004;286:F1193-F1201.

-23 Haq M, Norman J, Saba SR, Ramirez G, Rabb $\mathrm{H}$ : Role of IL-1 in renal ischemic reperfusion injury. J Am Soc Nephrol 1998;9:614-619.
24 Wang W, Faubel SG, Ljubanovic D, Mitra A, Kim J, Tao Y, Soloviev A, Reznikov L, Dinarello CA, Schrier RW, Edelstein CL: Endotoxemic acute renal failure is attenuated in caspase-1 deficient mice. Am J Physiol Renal Physiol 2005;288:F997-F1004.

25 Faubel S, Lewis EC, Reznikov L, Ljubanovic D, Hoke TS, Somerset H, Oh DJ, Lu L, Klein CL, Dinarello CA, Edelstein CL: Cisplatininduced $\mathrm{ARF}$ is associated with an increase in the cytokines IL-1 $\beta$, IL-18, IL- 6 and neutrophil infiltration in the kidney. J Pharmacol Exp Ther 2007;322:8-15.

26 Melnikov VY, Faubel SG, Siegmund B, Lucia MS, Ljubanovic D, Edelstein CL: Neutrophil-independent mechanisms of caspase-1and IL-18-mediated ischemic acute tubular necrosis in mice. J Clin Invest 2002;110: 1083-1091. 